\title{
COMMUNICATION
}

\section{Efficient Passivated Phthalocyanine-Quantum Dot Solar Cells}

Cite this: DOI: $10.1039 / \times 0 x x 00000 x$

\author{
Vicente M. Blas-Ferrando, ${ }^{a}$ Javier Ortiz, ${ }^{a}$ Victoria González-Pedro, ${ }^{b}$ Rafael S. \\ Sánchez, ${ }^{b}$ Iván Mora-Seró, ${ }^{b}$ Fernando Fernández-Lázaro ${ }^{a}$ and Ángela Sastre- \\ Santos*,a
}

Received 00th January 2012,

Accepted 00th January 2012

DOI: $10.1039 / \times 0 x \times 00000 x$

www.rsc.org/

The power conversion efficiency of CdSe and CdS quantum dot sensitized solar cells is enhanced by passivation with asymmetrically substituted phthalocyanines. The introduction of the phthalocyanine dye increases the efficiency up to $45 \%$ for CdSe and $104 \%$ for CdS. The main mechanism causing this improvement is the quantum dot passivation. This study highlights the possibilities of a new generation of dyes designed to be directly linked to QDs instead of the $\mathrm{TiO}_{2}$ electrodes.

Dye-sensitized solar cells (DSSC) have emerged as a low cost alternative to silicon. ${ }^{1}$ The most frequently used dyes are ruthenium complexes, ${ }^{2}$ porphyrins, ${ }^{3}$ phthalocyanines, ${ }^{4}$ althougheventually quantum dots ${ }^{5}$ are attractingmore and more attention.

Quantum dots (QDs) are nanocrystals of semiconductor materials undergoing phenomena of quantum confinement. ${ }^{6}$ They are heat resistant, low cost materials that can efficiently transfer electrons to large band gap semiconductorand whoseelectronic properties can be tuned by controlling the particle size, shape and composition. ${ }^{7}$ Moreover, they are quite promising light harvesting materials inDSSC for their ability to generate multiple charge carriers $^{8}$ under high energy irradiation and to inject hot electronsallowing to potentially overcome the theoretical limit of Shockley-Queisser. ${ }^{9}$ However, the efficiencies achieved with QDsensitized solar cells (QDSCs) are much lower (6-7\%) ${ }^{10}$ than those obtained with DSSC (13\%). ${ }^{11}$ Although the photocurrent is comparable in both devices, the voltage and the fill factor for QDSCs are lower due to the existence of electron transfer processes working against the cell cycle.

\footnotetext{
a División de Química Orgánica, Instituto de Bioingeniería, Universidad Miguel Hernández, 03202 Elche, Spain.Fax: 34-966658405; Tel: 34966658408; E-mail: asastre@umh.es

${ }^{b}$ Grup de DispositiusFotovoltaics i Optoelectrónics, Departament de Física,Universitat Jaume I, 12071 Castelló, Spain.E-mail: sero@uji.es $\dagger$ Electronic Supplementary Information (ESI) available: Synthesis and spectra of the new compounds.
}

Various strategies have been used to increase the efficiency of QDSC devices, such as doping of the semiconductor with transition metal ions ${ }^{12}$ or the use of plasmon resonances in metallic nanoparticles to generate charge carriers in adjacent semiconductor materials. ${ }^{13}$ The most extensively used semiconductor quantum dots, as $\mathrm{CdSe}$ or $\mathrm{CdS}$, only absorb in the visible. If a near infraredabsorbingdye was attachedto this kind of quantum dots, the resulting structure could maximize the absorption of the radiation and, in addition, reduce internal recombination,thus enhancing the photoinjected charge from the QD in a synergic process. ${ }^{14}$ In this way, bilayer electrodes ${ }^{15}$ sensitized with quantum dots and dyes or colloidal quantum dots acting as antennas that funnel absorbed light to the dye molecules via Förster resonance energy transfer (FRET) have been used. ${ }^{16}$ Alternative strategies such as supersensitization of CdSQDs with a near-infrared organic dye ${ }^{17}$ and sensitization of $\mathrm{TiO}_{2}$ films with covalently linked squaraine-CdSe quantum dots ${ }^{18}$ have improved the performance of QDSCs.Despite QDSCs and DSSCs follow the same working principles; there is a fundamental difference between both. QDspresent surface states that may play an important role in the recombination process and, consequently, in the final device performance. ${ }^{19,}{ }^{20}$ Photoexcited electrons and holes in QDs can recombine through QD surface states before being injected reducing the expected device photocurrent. ${ }^{19}$ On the other hand, electrons photoinjected into the $\mathrm{TiO}_{2}$ can also recombine before they arrive to the extracting contact. Again, surface states in QDs can favor this recombination that reduce the device open circuit potential. ${ }^{21}$ In this sense, efficient passivation of QD surface state is an strategy commonly employed to enhance QDSCs performance. $19,21,22$

Phthalocyanines (Pcs) are aromatic macroheterocycles which have been used successfully in DSSCs because they absorb intensely in the red spectral region, are able to inject into titanium oxide and are thermal and photochemicallyverystable compounds. ${ }^{23}$ Theirtendency to form aggregates on the $\mathrm{TiO}_{2}$ surface, which reduces the efficiency of solar cells, can be countered with the introduction ofbulky groups in the peripheral ${ }^{24}$ or apical ${ }^{25}$ positions going to efficiencies up to $6.5 \% .^{26}$ 
The chemical coordination of QDs to the Pc ring has not received much attention. FRET from QDs to different phthalocyanine photosensitizers has been demonstrated in a number of studies ${ }^{27}$ wherePcs and QDs wereunlinked. ${ }^{28}$ Until now, just a few articles have been published where the QDs are covalently linked to the Pcs showing efficient FRET $^{29}$ but no QD-DSSC have been studied yet.

Here we present the improvement inefficiency of QDSCs through their passivationwith covently linked phthalocyanines. Our approach represents a seminal work for the development of a new generation of dyes with multifunctional purposes, completing the light absorption range of QDs and, at the same time, passivating QDs surface, enhancing consequently the contribution from QD sensitization.For this purpose, a new bisphthalocyanine $(\mathbf{Z n P c S})_{2}$ 1containing two asymmetrically substituted Pcs has been synthetized (Scheme 1). $(\mathrm{ZnPcS})_{2} \mathbf{1}$ presents a disulfide group for the covalent bindingto QDs and bulky tert-butyl substituents to hinder possible aggregation.

$(\mathrm{ZnPcS})_{2} \mathbf{1}$ was prepared by acylation of the aminoethoxyphthalocyanine $2^{30}$ with 4,4'-dithio-bis-benzoyl chloride $^{31}$ in96 \% yield (Scheme 1 ).

(a)

Scheme 1Synthesis of bisphthalocyanine $(\mathrm{ZnPcS})_{2} \mathbf{1}$

The UV-vis absorption of the bisphthalocyanine $(\mathrm{ZnPcS})_{2}$ 1represented in Fig. 1a corresponds to a non-aggregated metallophthalocyanineexhibiting the typical sharp Q band transition at $675 \mathrm{~nm}$, withvibronic replica at $610 \mathrm{~nm}$, and a Soret band at around $350 \mathrm{~nm}$. This behaviour is quite important for an efective sensitization of the dye. ${ }^{23}$ Thenormalized fluorescence spectrum is given in Fig 1a (red curve) being roughly mirror symmetric with respect to the absorption spectrum. From the intersection of the normalized absorption and emission spectra, the zero-zero excitation energy $\left(\mathrm{E}_{0-0}\right)$ is determinedas $1.82 \mathrm{eV}$.
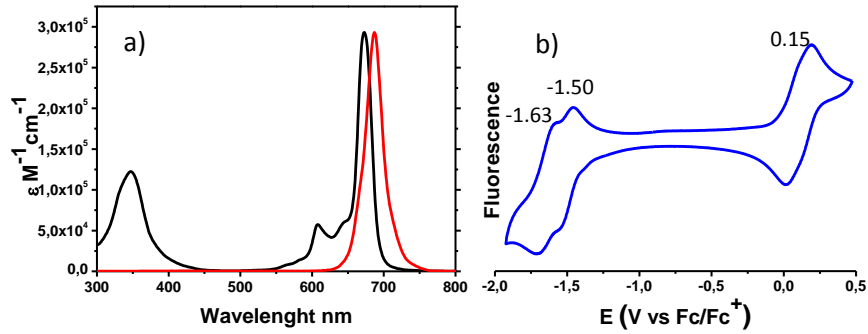

Fig. 1 (a) UV-Vis and fluorescence spectra of $(\mathrm{ZnPcS})_{2} \mathbf{1}$ in DMF as solvent. (b)Cyclic voltammogram $\left(100 \mathrm{mV} \mathrm{s}^{-1}\right)$ of $0.5 \mathrm{mM}(\mathrm{ZnPcS})_{2} 1$ in benzonitrile as solvent containing $0.10 \mathrm{M}$ of $\mathrm{TBAPF}_{6}$ as a supporting electrolyte.

Cyclic voltammetric studies of $(\mathrm{ZnPcS})_{2} \mathbf{1}$, performed on a benzonitrile solution containing $0.10 \mathrm{M}$ of $\mathrm{TBAPF}_{6}$ as supporting electrolyte, showed an oxidation peak at 0.49 Vand tworeduction peaks at $-1.13 \mathrm{~V}$ and $-1.29 \mathrm{~V}$ vs SCE (Fig. 1b). The electrochemically calculated HOMO-LUMO gap $\left(\mathrm{E}_{\mathrm{ox}}-\mathrm{E}_{\mathrm{red}}\right)$, $1.63 \mathrm{eV}$, is roughlyin agreement with the $\mathrm{E}_{0-0}$ energy, previously inferred from spectroscopic measurements.

The electrochemical characterization allows to determine the energy of the HOMO orbital and, together with the 0-0 transition energy, the energy of the LUMO orbital. Taking into account these values, together with the energy value for the conduction band of $\mathrm{TiO}_{2}(-4.2 \mathrm{eV})$ and the energy level of the polysulfide redox couple $(-4.0 \mathrm{eV})$, an energy level diagram can be sketched and the driving forces for electron injection and regeneration processes evaluated (Figure 2). The LUMO position for $(\mathrm{ZnPcS})_{2}$ lis higher in energy than the conduction band (CB) of the CdSeandCdS QD, which is a fundamental requisite in order to achievethe electron injection from the excited dye to the QDthermodynamically.

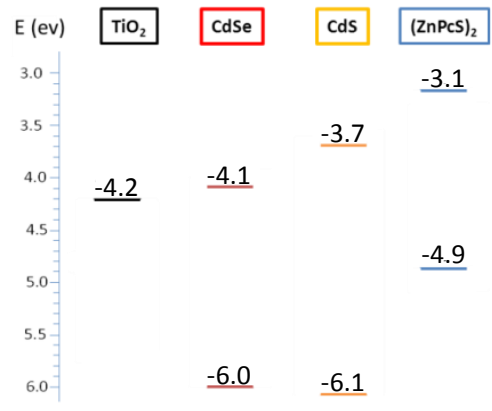

Fig. 2 Energy levels of $\mathrm{TiO}_{2}, \mathrm{CdSe}, \mathrm{CdS}$ and $(\mathrm{ZnPcS})_{2}$.

Our study began with CdSeQDs. They were prepared by the successive ionic layer adsorption and reaction (SILAR) method on $\mathrm{TiO}_{2}$ substrates, see SI. Half of these electrodes were immersed in a solution of the $(\mathrm{ZnPcS})_{2}$ 1during $24 \mathrm{~h}$ while the rest were used without this treatment. The comparison of the parameters of solar cells assembled with the Pctreatedelectrodes and those of solar cellsassembled with the Pcuntreatedelectrodeswill provide a measure of the efficacy of this protocol(Table 1). First, we studied the influence of the solvent in the process: chloroform, toluene and DMF were tested. Chloroform resulted in the worst results (entry 2). Change to toluene provided some improvements in cell parameters (entries 3 and 4). DMF, much more polar than the previous solvents, was then tested obtaining the best results with a significant increase inthe photocurrent and voltage, raising the efficiency to $2.9 \%$ (entry 5 ).

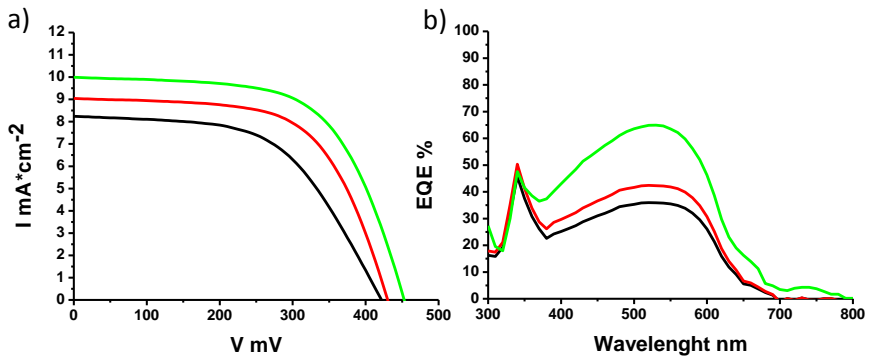

Fig. 3 (a) $J / V$ curve of QDSC device. (b)IPCE of device: black line CdSe ref, red line CdSe-DMFand green line QD CdSe-ZnPc. 


\begin{tabular}{|c|c|c|c|c|c|c|c|c|}
\hline Entry & QD-ZnPc & Solvent & $\begin{array}{l}\mathrm{t} \\
\mathrm{h}\end{array}$ & $\begin{array}{c}J_{S C} \\
\left(m A^{*} \mathrm{~cm}^{-2}\right)\end{array}$ & $\begin{array}{l}\mathrm{V}_{\mathrm{oc}} \\
(\mathrm{mV})\end{array}$ & $\mathrm{FF}$ & $\begin{array}{l}\eta \\
\%\end{array}$ & $\mathrm{EQE}^{\mathrm{a}} \%$ \\
\hline 1 & $\mathrm{CdSe}$ & - & - & 8.25 & 422 & 56 & 2.00 & 35 \\
\hline 2 & $\begin{array}{c}\mathrm{CdSe}-\mathrm{ZnPc} \\
1\end{array}$ & $\mathrm{CHCl}_{3}$ & 24 & - & - & 59 & 0.50 & - \\
\hline 3 & $\begin{array}{c}\mathrm{CdSe}-\mathrm{ZnPc} \\
1\end{array}$ & Tol & 12 & 5.35 & 400 & 63 & 1.34 & - \\
\hline 4 & $\begin{array}{c}\mathrm{CdSe}-\mathrm{ZnPc} \\
1\end{array}$ & Tol & 24 & 6.87 & 405 & 60 & 1.55 & - \\
\hline 5 & $\begin{array}{c}\mathrm{CdSe}-\mathrm{ZnPc} \\
1\end{array}$ & $\mathrm{DMF}$ & 24 & 9.98 & 453 & 60 & 2.90 & 64 \\
\hline 6 & $\mathrm{CdSe}$ & DMF & 24 & 9.02 & 430 & 54 & 2.22 & 40 \\
\hline 7 & $\mathrm{CdS}$ & - & - & 4.85 & 461 & 59 & 1.30 & 37 \\
\hline 8 & CdS-ZnPc 1 & $\mathrm{DMF}$ & 24 & 7.35 & 488 & 55 & 2.00 & 68 \\
\hline 9 & $\mathrm{CdS}$ & DMF & 24 & 5.93 & 510 & 51 & 1.50 & 50 \\
\hline 10 & $\mathrm{ZnPc} 1$ & DMF & - & 0.29 & 196 & 52.5 & 0 & - \\
\hline
\end{tabular}

Figure 3a shows the J/V curve comparing the Pc-untreatedCdSe device as reference, CdSe with DMF and with our CdSe$(\mathrm{ZnPcS})_{2}$ hybrid system. To rule out that the improvements were aneffect of the solvent used in the process, the Pcuntreated reference electrode was treated with DMF (entry 6), obtaining a solar cell with an efficiency of $2.22 \%$ (Figure. 3a).

Higher $V_{\mathrm{oc}}$ and $J_{\mathrm{sc}}$ wereobtained when $(\mathrm{ZnPcS})_{2} \mathbf{1}$ was attached to the CdSe quantum dot.However, Figure $3 b$ (external quantum efficiency versus wavelength)doesnot showthe expected improvement in the absorption area of phthalocyanines (600$700 \mathrm{~nm})$.

In addition, CdS-based QDSCs were also analyzed using the
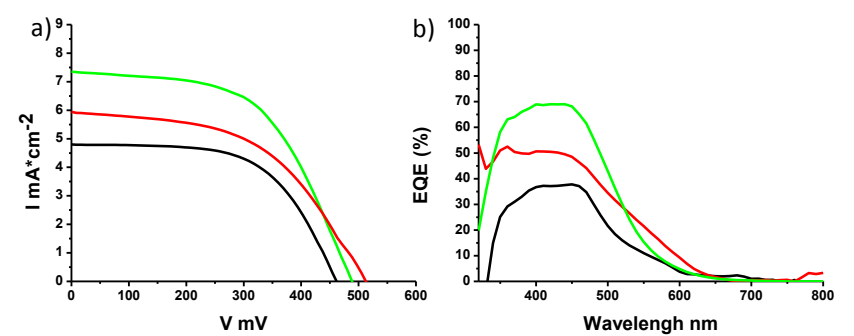

previous methodology. Electrodes were prepared in the same way as those ofCdSe. When one of these electrodes wastreated with $(\mathrm{ZnPcS})_{2} \mathbf{1}$ solution in DMF for $24 \mathrm{~h}$, a substantial increase in the photocurrent and improved fillfactor and voltage were achieved, doubling the cell efficiency (entry 7,8 and Figure 4a). Also, we rule out that the improvements were due to the effect of the solvent, obtaining a solar cell with an efficiency of $1.5 \%$ (entry 9, Figure. 4a).In order to discard that the direct sensitization of $\mathrm{TiO}_{2}$ by $(\mathrm{ZnPcS})_{2} \mathbf{1}$ was the major contribution to the photovoltaic response, aCdS-QD-free electrode was preparedadsorbing directly $(\mathrm{ZnPcS})_{2} \mathbf{1}_{\text {1ontoTiO }}$ (entry 10). No efficiency was observed, ruling out this possibility.

Figure $4 \mathrm{~b}$ shows the diagram EQE $v s$ wavelength for these cells. A significant increase of the EQE in the area between 300 and $500 \mathrm{~nm}$ is observed, however, it does not occurs the same in the area of 600-700 where the phthalocyanine absorbs. To make sure that the phthalocyanine is attached to the quantum dots, reflectance studies were conducted on the prepared electrodes. Figure 5 shows the appearance of the absorption band typical of the phthalocyanines confirming theirpresence.

Fig. 4(a) $J / V$ curve of QDSC device (b) IPCE of device. Black line CdS ref, red line CdS with DMF and green line QD CdS-ZnPc.
Table 1 Values obtained from the devices.

${ }^{\mathrm{a}} \lambda_{\max }=535 \mathrm{~nm}$ for CdSe and $\lambda_{\max }=440 \mathrm{~nm}$ for CdS.

Fig. 5Absorbancemeasurements of QD CdS ref black line, QD CdS$(\mathrm{ZnPcS})_{2}$ green line.

The observed increase of EQE in the light absorption region corresponding toCdS QDs indicates an effective beneficial interaction between QDs and dye molecules. We have also verified that the change of the absorption from the QDs (350$575 \mathrm{~nm})$, see Figure 5, for QD CdS- $(\mathrm{ZnPcS})_{2}$ sample can only justify an increase of $10 \%$ in the photocurrent, but a much large increment of $52 \%$, see Fig. $4 \mathrm{~b}$, is obtained. This fact together with the absence of EQE at the light absorption region of the dye suggest that the main effect of the interaction is the passivation of the QD surface. ${ }^{22}$

As it has been commented previously, surface states in QDs can act as recombination centers of photoexcited electron-hole pairs, before electron injection into electrode. Passivation of these states increases device IPCE and photocurrent. ${ }^{19}$ In addition, electrons photoinjected into $\mathrm{TiO}_{2}$ can also recombine through these QD surface states. This kind of recombination of

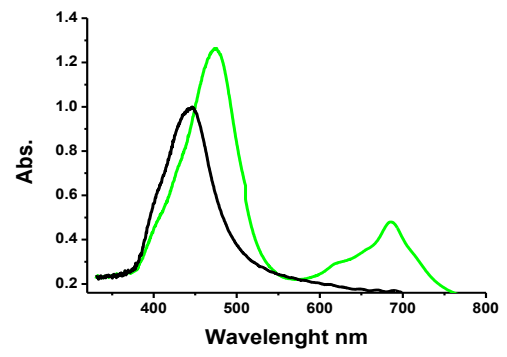

electrons in the $\mathrm{TiO}_{2}$ will move down the $\mathrm{TiO}_{2}$ Fermi level and, consequently, the cell photovoltage. ${ }^{21}$ To this extent, passivation also enhance photovoltage and FF.

In conclusion, we have successfully synthesized and characterized a new disulfide-bisphthalocyaninedye and we have explored its capacity as superpasivatingagents in QDSCs. With CdSe QDSC we studied the effect of solvent on the process and concluded that the best one was DMF.Pc-treated QDSCsshowed an improvement of the photocurrent that was not accompanied by a parallel increase of the IPCE in the absorption zone of the phthalocyanine. QD:( $\mathrm{ZnPcS})_{2}$ hybrid provided a major improvement in photocurrent and voltage, concluding that the main effect of QD-dye interaction is the passivation of QD surface.Reflectancestudies confirmed the link of phthalocyanine molecules to quantum dots. The introduction of the phthalocyanine dye increases the efficiency up to $45 \%$ for $\mathrm{CdSe}$ and $104 \%$ for CdS.Further efficiency increase,currently under study, could be expected from the development of new dyes,linked to QDs either directly or through a conjugated bridge, which in addition can extend the light harvesting region. This study opens the possibility of design a new generation of dyes with an adequate functionalization to be directly linked to QDs boosting the solar cell efficiency by a synergic interaction in several ways, QD passivation and extended light harvesting.

This work has been supported by the Spanish Ministry of Science and Innovation, GeneralitatValenciana and the European FEDER funds (CTQ2011-26455, PROMETEO 2012/010,ACOMP/2013/024and ISIC/2012/008). 


\section{Notes and references}

1 (a) B. O'Regan and M. Grätzel, Nature,1991, 353, 737-740.(b)D. Butler, Nature, 2008, 454, 558-559.

2 (a) Q. Yu, Y.Wang, Z. Yi, N. Zu, J. Zhang, M. Zhang andP.Wang, ACS Nano, 2010, 4, 6032-6038. (b) M. K. Nazeeruddin, F. De Angelis, S. Fantacci, A. Selloni, G. Viscardi, P. Liska, S. Ito, B. Takeru and M. Grätzel, J. Am. Chem. Soc., 2005, 127, 16835-16847.

3 S. Mathew, A. Yella, P. Gao, R. Humphry-Baker, B. F.E.Curchod, N. Ashari-Astani, L. Tavernell, U. Rothllsberger, Md. K. Nazeeruddin and M. Grätzel,Nat. Chem., 2014,6, 242-247.

4 (a) M. E. Ragoussi, J. J. Cid, J. H. Yum, G. de la Torre, D. Di Censo, M. Grätzel, M. K. Nazeeruddin and T. Torres, Angew. Chem. Int. Ed., 2012, 51, 4375-4378. (b) T. Ikeuchi, H. Nomoto, N. Masaki, M. J. Griffith, S. Mori, M. Kimura, Chem. Commun., 2014, 1941-1943.(c) E. M. Barea, J. Ortiz, F. J. Payá, F. Fernández-Lázaro, F. Fabregat-Santiago, Á. SastreSantos and J. Bisquert, Energy Environ. Sci., 2010, 3, 1985-1994.

5 (a) P. V. Kamat, J. Phys. Chem. C, 2008,112, 18737-18753. (b)I. MoraSeró and J. Bisquert, J. Phys. Chem. Lett., 2010, 1, 3046-3052. (c) I. J. Kramer and E. H. Sargent, ACS Nano, 2011, 5, 8506-8514.

6 D.Vanmaekelbergh and P. Liljeroth, Chem. Soc. Rev., 2005, 34, 299 312.

7 (a)W. W.Yu,L. H.Qu,W. Z.Guo and X. G.Peng, Chem. Mater., 2003, 15 2854-2860. (b) C. B.Murray,D. J. Norris and M. G.Bawendi, J. Am. Chem. Soc., 1993, 115, 8706-8715.(c)K. Tvrdya, P. A. Frantsuzovc and P. V. Kamat, PNAS, 2011, 108, 29-34.

8 (a) J. B. Sambur, T. Novet and B. A. Parkinson,Science, 2010,330, 6366. (b) O. E. Semonin, J. M. Luther, S. Choi, H. Y. Chen, J. Gao, A. J. Nozik and M. C. Beard,Science, 2011,334, 1530-1533.

9 (a) W. A. Tisdale, K. J. Williams, B. A. Timp, D. J. Norris, E. S. Aydil and X. Y. Zhu,Science, 2010, 328, 1543-1547. (b) P. V. Kamat,J. Phys. Chem. Lett. 2013, 4, 908-918.

10 (a) Z. Pan, I.Mora-Seró, Q. Shen, H. Zhang, Y. Li, K.Zhao, J. Wang, X.Zhong and J. Bisquert, J. Am. Chem. Soc. 2014, 136, 9203-9210. (b) J. Wang,I.Mora-Seró, Z. Pan, K. Zhao, H. Zhang, Y. Feng, G. Yang, X. Zhong and J. Bisquert, J. Am. Chem. Soc. 2013, 135, 15913-15922.

11 (a) A. G. Pattantyus-Abraham, I. J. Kramer, A. R. Barkhouse, X. Wang, G. Konstantatos, R. Debnath, L. Levina, I. Raabe, M. K. Nazeeruddin, M. Grätzel and E. H. Sargent,ACS Nano,2010, 4, 3374-3380. (b) P. V. Kamat,Acc. Chem. Res., 2012, 45, 1906-1915.

12 P. K. Santra and P. V. Kamat,J. Am. Chem.Soc., 2012, 134, 2508-2511.

13 C. Hägglund and S. P. Apell,J. Phys. Chem. Lett., 2012, 3, 1275-1285. (b) H. Choi, W.T. Chen and P. V. Kamat,ACSNano, 2012, 6, 4418-4427.

14 I.Mora-Seró, D. Gross, T.Mittereder, A. A.Lutich, A.Susha, T.Dittrich, A.Belaidi, R. Caballero, F.Langa, J. Bisquert and A. L. Rogach, Small,2010,6, 221-225.

15 M. Shalom, J. Albero, Z. Tachan, E. Martínez-Ferrero, A. Zaban and E. Palomares,J. Phys. Chem. Lett., 2010, 1, 1134-1138.

16 (a) S. Buhbut, S. Itzhakov, E. Tauber, M. Shalom, I. Hod, T. Geiger, Y. Garini, D. Horon and A. Zaban,ACSNano, 2010, 4, 1293-1298. (b) S. Buhbut, S. Itzhakov, D. Horon and A. Zaban,J. Phys. Chem. Lett., 2011, 2, 1917-1924. (c) R. Narayanan, A. Das, M. Deepa, and A. K. Srivastava, ChemPhysChem, 2013, 14, 4010-4021. (d) L. Etgar, J. Park, C. Barolo, V. Lesnyak, S. K. Panda, P. Quagliotto, S. G. Hickey, Md. K. Nazeeruddin, A. Eychmüller, G. Viscardi and M. Grätzel, RSC Adv., 2012, 2, 2748-2752.

17 H. Choi, R. Nicolaescu, S. Paek, J. Ko and P. V. Kamat,ACSNano, 2011, 5, 9238-9245.

18 H. Choi, P. K. Santra and P. V. Kamat,ACSNano, 2012, 6, 5718-5726.

19. N. Guijarro, J. M. Campiña, Q. Shen, T. Toyoda, T. Lana-Villarreal and R. Gómez, Phys. Chem. Chem. Phys., 2011, 13, 12024-12032.

20. I. Hod, V. González-Pedro, Z. Tachan, F. Fabregat-Santiago, I. MoraSeró, J. Bisquert and A. Zaban, J. Phys. Chem. Lett., 2011, 2, 30323035.

21. I. Mora-Seró, S. Giménez, F. Fabregat-Santiago, R. Gómez, Q. Shen, T. Toyoda and J. Bisquert, Acc.Chem. Res., 2009, 42, 1848-1857

22 M. S. de la Fuente, R. S. Sánchez, V. González-Pedro, P. P. Boix, S. G. Mhaisalkar, M. E. Rincón, J. Bisquert and I. Mora-Seró, J. Chem. Phys. Lett. 2013, 4, 1519-1525.
23 (a) L. Martín-Gomis, F. Fernández-Lázaro and Á. Sastre-Santos, J. Mater. Chem. A, 2014, 2,15672-15682.(b)M. E. Ragoussi, M. Ince and T. Torres,Eur. J. Org. Chem. 2013, 6475-6489.

24 (a) S. Mori, M. Nagata, Y. Nakahata, K. Yasuta, R. Goto, M. Kimura and M. Taya,J. Am. Chem. Soc.,2010, 132, 4054-4055. (b) M. GarcíaIglesias, J. H. Yum, R. Humphry-Baker, S. M. Zakeeruddin, P. Péchy, P. Vázquez, E. Palomares, M. Grätzel, M. K. Nazeeruddin and T. Torres,Chem. Sci., 2011, 2, 1145-1150.

25 (a) L. Martín-Gomis, E. M. Barea, F.Fernández-Lázaro, J. Bisquert and Á. Sastre-Santos,J. PorphyrinsPhthalocyanines, 2011, 15, 1004-1010.(b) B. Lim, G. Y. Margulis, J. H. Yum, E. L. Unger, B. E. Hardin, M. Grätzel, M. D. McGehee and A. Sellinger,Org. Lett., 2013, 15, 784-787.

26 M. E. Ragoussi, J. -H. Yum, A. K. Chandiran, M. Ince, G. de la Torre, M. Grätzel, M. K. Nazeeruddin, T. Torres, ChemPhysChem., 2014, 15, 1033-1036.

27 (a) S. Dayal, R. Krolicki, Y. Lou, X. Qiu, J.C. Berlin, M.E.Kenney and C. Burda, Appl. Phys. B, 2006,84, 309-315. (b) M. Idowu, J. Y. Chen and T. Nyokong, New J. Chem., 2008,32, 290-296.(c) J. Ma, J. Y. Chen, M. Idowu and T. Nyokong, J. Phys. Chem. B, 2008,112, 4465-4469. (d) S. Dayal, Y. Lou, A.C.S. Samia, J.C. Berlin, M. E. Kenney and C. Burda, J. Am. Chem.Soc., 2006,128, 13974-13975.

28 (a) S. Moeno, E. Antunes, S. Khene, C. Litwinski and T.Nyokong,Dalton Trans., 2010, 39, 3460-3471.(b) A.Erdoğmus, S. Moenoa, C. Litwinskia and T.Nyokong, J. Photochem. Photobiol., A,210, 2010, 200-208.

29 (a) S. Dayal, J. Li, Y.S. Li, H. Wu, A.C.S. Samia, M. E. Kenney and C. Burda, Photochem.Photobiol., 2007,84, 243-249. (b) J. Britton, E. Antunes and T.Nyokong, Inorg. Chem. Commun., 2009,12, 828-831. (c) J. Britton, E. Antunes and T.Nyokong, J. Photochem. Photobiol., A, 2010, 210, 1-7. (d) W. Chidawanyika, C.Litwinski, E. Antunes and T.Nyokong, J. Photochem. Photobiol., A, 2010,212, 27-35.

30 S. Fukuzumi, K. Ohkubo, J. Ortiz, A. M. Gutiérrez, F. Fernández-Lázaro and Á. Sastre-Santos,J. Phys. Chem. A,2008,112, 10744-10752.

31 K. Takeda, A. Kuwahara, K. Ohmori and T. Takeuchi,J. Am. Chem. Soc.,2009, 131, 8833-8838.

32 E. Palomares, M.V. Martínez-Diaz, S.A.Haque, T. Torres and J.R. Durrant,Chem. Commun. 2004, 2112-2113.

33 J.Gierschner, J.Cornil and H.J.Egelhaaf, Adv. Mater., 2007,19, 173191. 